DOI 10.37882/2223-2982.2021.12-2.10

\title{
НРАВСТВЕННАЯ СОСТАВЛЯЮЩАЯ ВОСПИТАТЕЛЬНОГО ПРОЦЕССА СОВРЕМЕННОЙ МОЛОДЕЖИ
}

\section{SPIRITUAL AND MORAL COMPONENT OF THE EDUCATIONAL PROCESS OF MODERN YOUTH}

\author{
M. Gataeva \\ Z. Okazova \\ Z. Sulumkhanova
}

Summary: The levels of spirituality and morality are the main features of a person, more precisely, spirituality is a set of basic norms and rules of ethology in society, and spirituality presupposes a description of the value of the degree of consciousness, the individual's striving for a specific goal. Together, spirituality and morality constitute the basis of the individual. At the present stage, moral education is positioned by most of the practicing teachers as a multifaceted problem that requires a creative solution. Recently, in the period of ongoing social changes in the world, qualitatively new goals of the educational process have emerged. The goal is to consider the spiritual and moral component of the educational process of the younger generation. For this study, it is important to note that not only with regard to the readiness of modern youth to accept new moral and spiritual norms, but in general - the current state of Russia in the field of social consciousness - is characterized by a new rise of humanistic, educational thinking. This allows you to take a fresh look at the pressing problem. Spiritual and moral education is an organized process of purposeful pedagogical influence on the moral and spiritual sphere of the student's personality, which is considered as a kind of system-forming inner world.

Keywords: educational process, modern youth, spirituality, morality, morality.
Гатаева Мата Сайд-Салаховна

Чеченский государственный педагогический университет, Грозный gataeva@mail.ru

Оказова Зарина Петровна

профессор, Чеченский государственный педагогический университет, Грозный okazarina73@mail.ru

Сулумханова Залина Шелиловна Чеченский государственный педагогический университет, Грозный

iinda.sulumkhanova@bk.ru

Аннотация: Уровни духовности и морали являются основными чертами человека, точнее, духовность - это совокупность основных норм и правил этологии в обществе, а духовность предполагает описание ценности степени сознания, стремления индивида к конкретной цели. В совокупности духовность и мораль составляют основу индивида. На современном этапе моральное воспитание позиционируется большей частью практикующих учителей как многогранная проблема, требующая творческого решения. В последнее время в период происходящих социальных изменений в мире появились качественно новые цели образовательного процесса. Цель - рассмотреть духовно-нравственную составляющую образовательного процесса подрастающего поколения. Для данного исследования важно отметить, что не только в отношении готовности современной молодежи к принятию новых моральных и духовных норм, но и в целом - нынешнее состояние России в области общественного сознания - характеризуется новый взлет гуманистического, образовательного мышления. Это позволяет по-новому взглянуть на насущную проблему. Духовно-нравственное воспитание - это организованный процесс целенаправленного педагогического воздействия на нравственнодуховную сферу личности ученика, которая рассматривается как своего рода системообразующий внутренний мир.

Ключевые слова: образовательный процесс, современная молодежь, духовность, нравственность, мораль.

новые цели образовательного процесса. В частности, были пересмотрены существующие классические принципы с критической позиции. Проблема духовности и морали отражена в произведениях В.М. Бехтерева, Л. Гумилева С.Л. Соловейчук, Н.Ю. Калуженской.

Цель - рассмотреть духовно-нравственную составляющую образовательного процесса подрастающего поколения.

\section{Методы исследования}

Теоретический, заключающийся в анализе отечественных и зарубежных литературных источников по проблеме обеспечения безопасности образовательных 
учреждений.

\section{Результаты исследования и их обсужление}

С точки зрения психологов-практиков духовно-нравственный личностный потенциал подразумевает непосредственно интегральную индивидуальность личности, он на современном этапе развития общества востребован, есть возможность его экстраполирования для конкретной цели.

В ходе исследований, успешно завершенных в научной школе В.В. Белоуса, создан шаблон типологии комплексной индивидуальности, в ее основе лежит разносторонность, когда учтены все необходимые динамические и содержательные показатели психической действительности [1].

На основании проведенных исследований определены:

- социальная значимость результатов деятельности с позиции общества;

- процедурный аспект деятельности подразделения;

- особенности субъектно-объектных взаимоотношений общества и индивида.

Что касается описания субъективно-объективных взаимоотношений общества и индивида, тут ярко выражено сопереживание, предусматривающее желание быть добрым, способность воспринимать много людей в режиме реального времени.

Духовная и нравственная целостность порождает необходимые для жизни навыки и этологические привычки, которые обеспечивают жизнедеятельность человека в обществе и позволяют корректировать комплекс морально-ценностных ориентаций.

Духовно-нравственное развитие - главная задача семейного воспитания. По мнению Э. Басанова, «Семья - главный социальный институт, через который ребенок включается в социальные отношения. Дело в том, что ребенок в семье может усваивать ценности, нормы поведения и формировать собственные представления о жизни».

О.Г. Дробницкий в своих исследованиях трактует нравственные качества человека. Для него это характеристики или свойства индивидуального сознания и этологии, которые играют коллективистскую и гуманистическую роль. Они определяются добровольным выбором, основанным на общественном мнении определенного класса или социальной группы. Моральные качества человека - это прежде всего системный образовательный объект, неотъемлемый результат развития и воспитания [3].

Формирование нравственных качеств современной личности, отвечающей потребностям общества, основывается на следующих концепциях и принципах:

- моральные качества человека социально обусловлены, отличаются классовым характером, историко-конкретным, это отражение социальных отношений, существующих в той социальной среде, в зеркале этологии сознания и личности, где она формируется;

- Моральные качества человека - это совокупность элементов, составляющих его нравственный строй, взаимосвязанных, способных раскрывать моральное сознание и индивидуальное поведение во всем их богатстве содержания и формы.

О.Г. Дробницкий, анализируя типологию нравственных качеств человека, трактовал это понятие как один из общеобязательных способов выражения нравственных потребностей [6].

В трудах В.А. Блюмкина была создана единая типология и система нравственных характеристик личности. Он выделил около 430 моральных характеристик человека непосредственно на основе структурных, функциональных и содержательных аспектов и обосновал эту классификацию. Он делит весь спектр моральных характеристик человека на 4 типа актуальных моральных характеристик, которые характеризуются ярко выраженными моральными красками:

- коллективизм, подразумевающий развитое чувство товарищества и солидарности, чувство долга и ответственности;

- гуманистические качества, мы говорим прежде всего о человечности, благородстве, человеческом доверии, доброжелательности, чуткости, такте, самоуважении, гордости, смирении и простоте;

- интегральные характеристики, определяющие достижение индивидом определенных целей нравственного регулирования, то есть нравственного действия, предполагающего способность к альтруизму, готовность к героизму, соперничеству, справедливости, благодарности, незаинтересованности, зависти;

- Качества, определяющие уровень морального регулирования, в частности чувство чести, честности, порядочности, искренности, открытости, правдивости, принципиальности, верности и пр.

Он также выделил 3 типа «косвенных» моральных качеств, которые не имеют четко выраженного морального компонента, достаточно морально нейтральны, но имеют сильные моральные коннотации в конкретной жизненной ситуации. Эти типы человеческих мораль- 
ных качеств находятся на перекрестке морали с другими формами общественного сознания и практики:

- идеологические, моральные и морально-политические характеристики: совесть и идеология, патриотизм и интернационализм, гражданство;

- морально-экономические и морально-коммерческие характеристики: трудолюбие, дисциплина, инициативность, совесть, экономия, работоспособность, организованность, инициативность, инициативность, настойчивость;

- морально-прагматические ценности: мудрость, хорошее образование, хорошее образование, умеренность, умение испытывать большую любовь, общительность.

Все вышеперечисленные типы моральных качеств человека являются обязательными составляющими сознания и этологии нового человека. Разработал В.А. Классификация Блюмкина - вектор проектирования и реализации нравственного воспитания современной личности на этапе образовательного процесса в ВУЗе.

Моральные категории являются руководством к действию только тогда, когда они глубоко поняты и экстраполируются на уровень моральных убеждений. Эти сформированные убеждения и привычки нравственного поведения говорят о воспитании человека с точки зрения нравственности и зрелости. Объединение нравственных чувств, нравственного поведения и нравственной совести, воплощенных в устойчивых нравственных качествах, является основным показателем соответствия образовательного процесса нравственному развитию личности: из-за халатности, ошибок участников образовательного процесса в образовательном деятельность, отметка, наложенная нездоровой средой, образовательная пренебрежение подростков и юношей является антисоциальной и устойчивой, когда самостоятельной и исходной психолого-педагогической задачей является реабилитация, которая предполагает выполнение определенных воспитательно-психологических мероприятий и создание особых условий для их реализации [5].

Набор отношений между студентами и другими участниками образовательного процесса должен быть организован таким образом, чтобы можно было включить в него модель нравственных качеств, необходимых современному человеку, а именно: гражданскую совесть, патриотизм, коллективизм, идеологию, взаимовыручка, трудолюбие и т.д. качества объединяет сущность нравственного отношения к людям, умение видеть каждое их действие с точки зрения общества или на благо общества. Важно развить умение оценивать последствия своих действий.

Таким образом, духовно-нравственные качества обозначают совокупность норм, правил и моральных прин- ципов, которые принимаются и усваиваются человеком, которые используются добровольно и правильно под влиянием возникших человеческих чувств. Поэтому на уроках биологии имеет смысл тренировать следующие духовно-нравственные качества человека, такие как трудолюбие, уважение к труду, совесть и забота.

Трудолюбие - это черта характера, сочетающая в себе позитивное отношение человека к процессу профессиональной деятельности и общечеловеческие ценности. Уважение - это отношение одного человека к другому, признание достоинства человека. Добросовестность это способность комплексно выполнять свои обязанности и ответственность. Взаимопомощь - помощь двум и более людям.

В ходе анализа разработанных подходов к разграничению тех или иных духовных явлений были выделены центральные группы духовно-моральных характеристик, предусматривающих следующие особенности мировоззрения и духовной культуры:

- общесоциальное, а именно, отношение к обществу и государству: верность конституции государства и его гражданам, патриотизм, уважение к историческим основам государства, государства и армии, любовь к труду, чуткость к людям, правдивость;

- внутриличностное, или отношение к себе: достоинство, скромность, платежеспособность, амбициозность, чувство собственного достоинства, способность к самоконтролю, готовность к самосовершенствованию и самообразованию, критический взгляд на свои действия и поступки, сравнение их с ценностями, общество, армия и коллектив и др.

- межличностное или отношение к коллективу, институту семьи, родителям, родственникам, друзьям, коллегам и подчиненным: душевное благородство, товарищество, доброжелательность, честность, порядочность, толерантность, соблюдение правил, пунктуальность, честность, личный пример, соблюдение воинских традиций, несоблюдение/соблюдение моральных норм и др.

Духовная составляющая урока напрямую помогает учащимся усвоить и понять систему ценностей. Следовательно, обучение происходит личным примером, а моральный компонент - это поддержка в формировании этологической модели, чувств и отношения, в комплексе демонстрирующих идеологическую позицию в социуме каждого человека. Подростковый возраст - период интенсивного формирования иерархии ценностных ориентаций, оказывающих воздействие на воспитание нравственно-духовной составляющей личности.

Формирование личности, как правило, определяется 
передачей системы ценностей, «наработанных»в период становления общества, созвучием межкультурных, межнациональных отношений в Российской Федерации на современном этапе.

Реализация в современной трактовке стратегии развития Российской Федерации немыслима без восстановления и развития морально-духовного потенциала системы формирования толерантного сознания [4].

Проблемы духовно-нравственного воспитания отличает чрезвычайно высокая актуальность для развития общества. Передовая педагогическая свидетельствует, что современные, неустойчивые социально-экономические условия развития общества, негативно влияют на нравственность подрастающего поколения, потому что в современном обществе нет ориентиров нравственных и духовных социально-общественных отношений. Возросло количество детских психических заболеваний, дезадаптация подрастающего поколения в социальной среде. Детский суицид на фоне нестабильных социально-бытовых условий стал одной из трагедий общества сегодня. Определенное влияние оказали и стремительно возросшие учебные нагрузки в образовательных учреждениях.

В ходе оценки духовно-нравственных проблем современного российского общества отечественные ученые-практики пришли к выводу, что практически полная смена законодательной базы особенно больно сказалась на сфере социальной и экономической защиты населения.

Все вышеизложенное привело к смене нравственного климата в России, что предполагает целесообразность качественно нового научного осмысления и, как следствие, поиска методов и способов воспитания духовно-нравственных ценностей путем, свойственным только для России, но с учетом накопленного мирового и отечественного опыта». Формирование личности происходит путем присвоения ею общественно-политического опыта человечества в процессе предметно-практической деятельности.

По мнению К.Д. Ушинский отмечал, что педагогические системы, несмотря на множество названий и сходств значительно отличаются друг от друга. По мнению Н.В. Соловьевой «наша страна второе десятилетие возрождает некогда утерянные ею знания о закономерностях влияния социокультурной среды на различные слои общества. Подобная тенденция обусловлена осознанием реальной ситуации современной российской действительности для развития личности».

По мнению А.В. Волошинова гуманизация образования представляет собой три великие смыслообраза, в трех ликах культуры - Истине, Красоте и Добре.

В исследованиях Н.Д. Никандров отмечал, что истинная культура для большей части молодежи сегодня не востребована, что можно объяснить глубоким кризисом образовательной системы, проявившимся в недостаточной гуманитарной составляющей, ибо духовной составляющей нет в приоритетных направлениях развития науки, также недостаточен воспитательный компонент содержания образования, отсутствует и национальная идея. Возникла необходимость в государственной концепции духовно-нравственного развития молодежи, адаптированной к социальным законам российского общества.

Именно государству отводится роль создания условий для свободного развития личности, полного удовлетворения ее потребностей и интересов.

Целесообразно приобщать подрастающее поколение к шедеврам национального искусства, проводить в образовательных учреждениях выставки народных костюмов и ремёсел. Показывать драматические спектакли, поставленные по произведениям классиков, а также концерты популярной классической музыки, литературные встречи с писателями, поэтами. Все это важно в воспитании личностных качеств подрастающего поколения: художественный вкус и творческие способности. Однако это возможно при условии единой целенаправленной системы гуманитарного образования, а не там, где осуществляют учебно-воспитательную деятельность, как посчитают нужным.

Современная семья, являясь основным элементом социокультурной среды, в которой должно происходить формирование и усвоение культурных и образовательных ценностей подрастающего поколения, характеризуется низким уровнем материального обеспечения (60\%) и нестабильно по статистике. Это означает, что дети являются участниками конфликтных ситуаций, родители не всегда педагогически компетентны и в семье взрослые берут на себя право регулировать права ребенка, добиваясь их безоговорочного послушания. Следовательно, родительско-детские и супружеские отношения сложны и требуют позитивной семейной психотерапии.

Средства массовой информации, Интернет, желтая пресса, содержание телепрограмм, реклама разрушительно воздействуют на личность подростков, эффективно превращая их в опасную силу для общества. Учитывая сложившуюся крайне опасную ситуацию. Отсюда следует, что необходимо, прежде всего, усилить гуманитарную направленность образования и применить цензуру в рамках конституции страны [2].

Для данного исследования важно отметить, что не 
только в отношении готовности современной молодежи к принятию новых моральных и духовных норм, но и в целом - нынешнее состояние России в области общественного сознания - характеризуется новый взлет гуманистического, образовательного мышления. Это позволяет по-новому взглянуть на насущную проблему. Рассматривая причины разрушения, характерные для юношеской среды этого периода, исследователи указывают на значительный вес как духовных, так и аксиологических причин. Так, А.Л. Корженко констатирует следующее: формирование и развитие современного общества происходит без оглядки на ценностные приоритеты; рассматриваемые процессы, как правило, характеризуются хаосом; разнообразие ценностей в гражданской позиции молодежи; отсутствие возможностей воплощения ценностных ориентаций молодежи приведет к распаду духовного образования; возрастает степень рассогласованности систем образования, что приводит к генерации противоположных ценностей и негативных тенденций в общественном сознании; снижение роли и важности школы и семьи в образовательном процессе; получение прагматического образования; рост индивидуализма, кризис коллективизма в современной молодежной среде.

Поэтому считается совершенно адекватным обращение государства, как и всего общества, к народным традициям нравственного и морального воспитания; активизация непосредственно диалога с представителями важных государственных структур, новый анализ проблемы взаимоотношений науки и общества. Это требует тщательного анализа выявленной нами проблемы.

Взаимодействуя с окружающего мира под направленным воздействием факторов педагогики, создается идеальное отношение к реальному миру, в ходе которого учащиеся приобретают необходимый уровень морального опыта, а также опыт морально-обоснованного поведения. Педагогическое воздействие может быть разнообразным: не только по продолжительности, но и по степени интенсивности.

Студенты получают позитивный опыт нравственного поведения при общении с окружающей средой, людьми и целенаправленным педагогическим воздействием. Биологические факторы, социальные условия, общение могут оказывать особое воздействие на эффективность формирования нравственных и моральных качеств человека. Тем не менее, ведущую роль играет педагогическое влияние, в основе которого лежит целенаправленное на личность воздействие.

Нравственность - это совокупность базовых правил поведения и принципов человека в ходе взаимодействия с обществом, с самим собой. Эта связь лежит в основе личности, где духовность выступает вектором движения, направленного на самосовершенствование, самообразование, саморазвитие.

В этой ситуации итоговые параметры могут быть получены путем проведения не только анализа, но и самоанализа учебной деятельности - с помощью экспертного метода. Второй критерий - это измерение реализации условий обучения, что напрямую связано с учетом специфики среды (В.А. Караковский, Л.И. Новикова, В.Д. Семенов и др.). В этом критерии есть такие показатели, как: психологическая и моральная атмосфера в семье, круг неформального общения. Информацию по этим параметрам можно получить при выполнении совместной работы с родителями, сверстниками, учителями методом наблюдения; с ежедневным общением. Третий критерий - это измерение реализации учебного взаимодействия. Оценка степени его эффективности проводится по отложенной и немедленной реакции на непосредственно достигнутое воздействие.

Таким образом были определены 3 уровня формирования духовно-нравственных ценностей: низкий (эмоциональный и эмпирический); рейтинг контента (средний); высокий (активный и творческий).

\section{Выво $\triangle$}

Духовно-нравственное воспитание - это организованный процесс целенаправленного педагогического воздействия на нравственно-духовную сферу личности ученика, которая рассматривается как своего рода системообразующий внутренний мир.

\section{ЛИТЕРАТУРА}

1. Ажиев А.В., Калманова Ц.А., Гадаборшева 3.И., Тотиков 3.В., Басиева А.В. Здоровьесберегающие технологии в образовательном процессе // Свидетельство о регистрации базы данных 2020621563, 27.08.2020. Заявка № 2020621462 от 21.08.2020.

2. Ажиев А.В., Оказова 3.П., Калманова Ц.А. Методы педагогических исследований // Свидетельство о регистрации базы данных 2020620376, 28.02.2020. Заявка № 2020620221 от 18.02.2020.

3. Ахмеджанова Г.Т. Духовно-нравственное воспитание - одно из ведущих направлений в воспитании кадет / Г.Т. Ахмеджанова // Материалы Международной научно-практической конференции «Транспорт, наука, образование XXI века». Барнаул. 2017. С. 114-117.

4. Кемалова Л.И. Духовно-нравственное воспитание личности: единство образования, просвещения и воспитания / Л.И. Кемалова // Вестник Международ- 
ных научных конференций. 2015. № 8. С. 27-33.

5. Осипов Э.В. Воспитание семейных ценностей как важное звено духовно-нравственного воспитания личности / Э.В. Осипов // Материалы Всероссийской научно-практической конференции «0бразовательная среда: новые методы, направления и пути развития». Москва. 2019. С. 77-85.

6. Шестак М.А. Патриотическое воспитание как одно из направлений духовно-нравственного развития личности / М.А. Шестак // Материалы Всероссийской научно-практической конференции «Инновационные оздоровительные и реабилитационные технологии». Саратов. 2016. С. 368-373.

○ Гатаева Мата Сайд-Салаховна (gataeva@mail.ru), Оказова Зарина Петровна (okazarina73@mail.ru),

Сулумханова Залина Шелиловна (iinda.sulumkhanova@bk.ru).

Журнал «Современная наука: актуальные проблемы теории и практики»

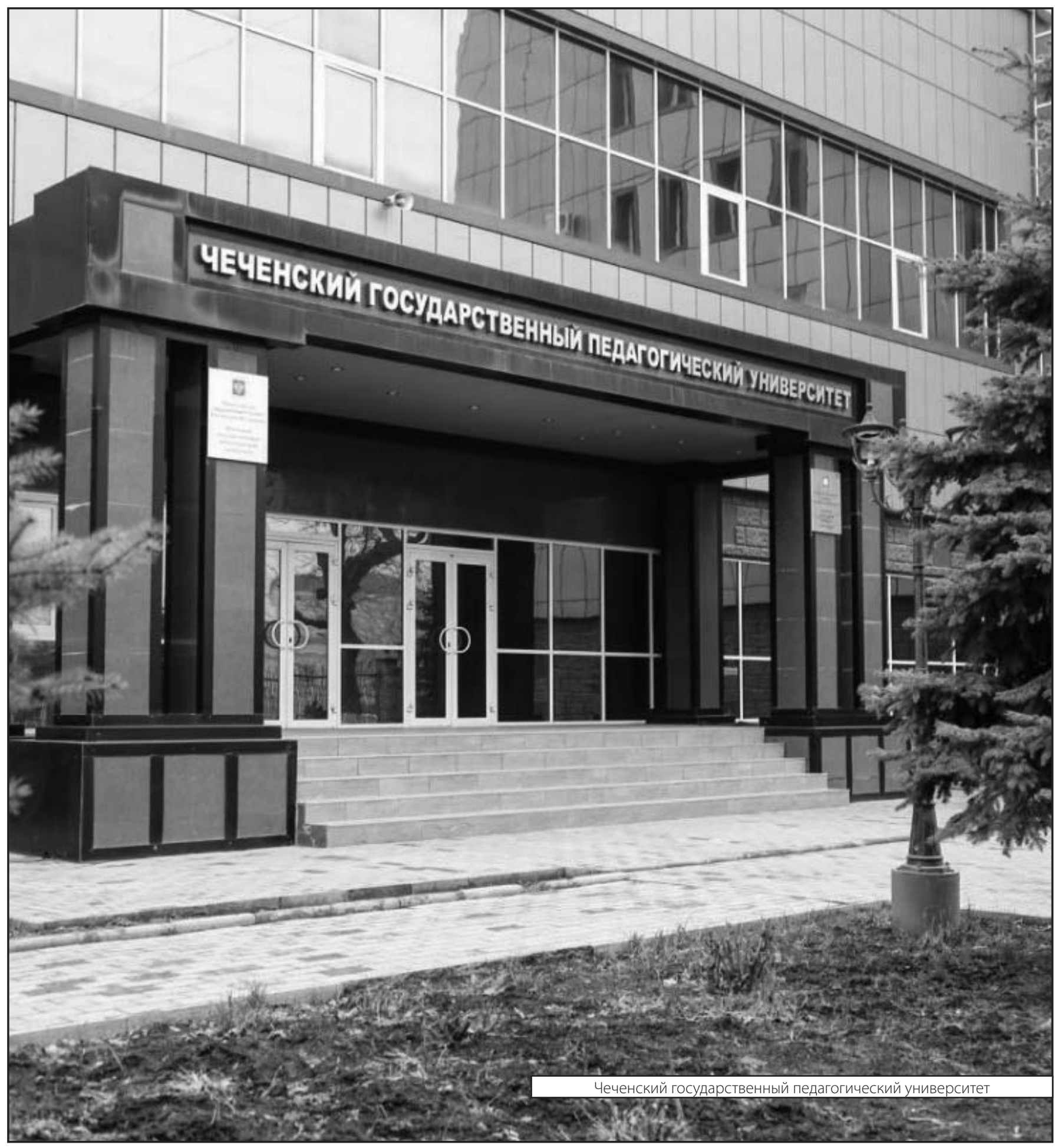

